DE

M E D I C I N A

T R O P I C A L

$\mathrm{DE}$

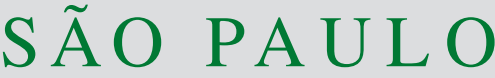

JOURNAL OF THE SÃO PAULO INSTITUTE OF TROPICAL MEDICINE

\section{Prevalence of Hepatitis B and C virus infection among alcoholic individuals: importance of screening and vaccination}

\author{
Vanessa Faria Cortes ${ }^{1,2}$, Angela Taveira ${ }^{1}$, Helena Medina $\mathrm{Cruz}^{2}$, Amanda \\ Alves Reis ${ }^{1}$, Jéssica Silva Cezar ${ }^{1}$, Brener Santos Silva ${ }^{1}$, Cintia Feliciano \\ D’Assunção', Elisabeth Lampe ${ }^{2}$, Livia Melo Villar ${ }^{2}$
}

(1)Universidade Federal de São João del Rei, Laboratório de Bioquímica Celular, São João del Rei, Minas Gerais, Brazil

(2)Instituto Oswaldo Cruz - FIOCRUZ, Laboratório de Hepatites Virais, Rio de Janeiro, Rio de Janeiro, Brazil

Correspondence to: Livia Melo Villar Instituto Oswaldo Cruz - FIOCRUZ, Laboratório de Hepatites Virais, Pavilhão Helio e Peggy Pereira, Av. Brasil, 4365, Térreo, sala B09, Manguinhos, CEP 21045900, Rio de Janeiro, RJ, Brazil. Tel: +55 $21212562-1918$,

Fax: +55 $212270-6397$

E-mail: Ivillar@ioc.fiocruz.br

Received: 05 November 2016

Accepted: 31 March 2017

\section{ABSTRACT}

Drug users have been reported to have an increased risk for acquisition of viral hepatitis. This study aims to evaluate the prevalence of HBV and HCV infection and usefulness of saliva for $\mathrm{HBsAg}$ and anti-HCV detection in alcoholic patients. A total of 90 alcoholic patients were recruited in 2013. HBsAg and anti-HCV were tested in serum and saliva, anti-HBc and anti-HBs were tested in serum using commercial enzyme immunoassays (EIA). Using serum samples, anti-HCV, HBsAg, anti-HBc and anti-HBs prevalences were 5.6\%, 0\%, $15.7 \%$, and $29.2 \%$. HBsAg detection in saliva showed $100 \%$ of specificity and anti-HCV detection demonstrated $100 \%$ of sensitivity and $94.7 \%$ of specificity. Low prevalence of $\mathrm{HBV}$ and high prevalence of anti-HCV were found and reinforced the recommendation of $\mathrm{HBV}$ vaccination to avoid the acute and chronic cases and $\mathrm{HCV}$ screening in this group to identify cases for antiviral therapy. Saliva samples could be used for anti-HCV detection in this population, what could increase the diagnosis access.

KEYWORDS: Hepatitis C virus Hepatitis B virus. Prevalence. Saliva. Alcoholic patients.

\section{INTRODUCTION}

Drug and alcohol abuse are important risk factors for the acquisition of hepatitis B and $\mathrm{C}$ viruses (HBV and HCV). Alcohol is consumed in several regions of the world and in different cultural contexts. In Brazil, a nationally representative household survey conducted in 2013 showed that current drinking prevalence was $26 \%$, with an average age of initiation of 18.7 years ${ }^{1}$. In alcoholic individuals from Turkey, HBV and HCV prevalences of $16.3 \%$ and $8.2 \%$, respectively, have been reported ${ }^{2}$, but few studies were conducted to evaluate the prevalence of these infections in alcohol-dependent patients in Brazil ${ }^{3,4}$.

Saliva samples could be an alternative specimen for HBV and HCV diagnosis due to the easy and painless collection and low cost compared to blood collection. $\mathrm{HCV}$ and HBV markers have been detected among saliva samples ${ }^{5,6}$, but there is no information regarding the usefulness of these samples for detecting HBV and $\mathrm{HCV}$ markers in alcohol dependence patients.

This study aims to determine HCV and HBV prevalence and associated risk factors for HBV infection among alcohol-dependent patients and the usefulness of saliva samples for HBsAg and anti-HCV detection in this group. 


\section{MATERIALS AND METHODS}

\section{Study Population}

A total of 90 men aged 18 to 74 years old were recruited in a house for addicts in Minas Gerais State (Southeast region of Brazil) from August to December 2013. A nonprobabilistic sampling was used and all individuals that fulfilled inclusion criteria were recruited in this period.

Inclusion criteria were: any race, age above 18 years old, alcohol dependence confirmed by patient records and/ or Alcohol, Smoking and Substance Involvement Screening Test $(\mathrm{ASSIST})^{7}$ score $>27$ points, good comprehension and verbal communication at the moment of recruitment, and agreeing to participate after signing the Informed Consent Form (ICF). Exclusion criteria were the absence of alcoholic abuse, problematic behavior, or confusion at the time of recruitment, as well as not agreeing with the terms of the ICF.

\section{Questionnaires}

All participants answered two questionnaires, one containing items about socio-demographic status and risk factors for viral hepatitis, and another one named ASSIST V $3.0^{7}$ that determines the risk score for illicit substances like alcohol, which falls into a low risk (0-10), moderate risk (11-26) or high risk $(+27)$ and determines the most appropriate intervention for the respective level of use.

ASSIST is a brief screening questionnaire to determine the pattern of use of psychoactive substances. The questionnaire has seven domains related to the consumption of psychoactive substances, and each domain contains ten questions. This instrument was validated in an international study including Brazil, and demonstrated good reliability and feasibility ${ }^{7}$.

\section{Sample Collection and testing for HBV and HCV}

Blood samples were collected by venipuncture to obtain serum and saliva using a commercial device (Salivette, Sarstedt) and processed as previously described ${ }^{5,6}$.

Serum samples were tested for HBsAg (HBsAg One, RADIM, Pomezia, Italy), total anti-HBc (Diasorin, Italy), anti-HBs (Diasorin, Italy), and anti-HCV (HCVab, Radim, Pomezia, Italy) using EIA following the manufacturer's information. Anti-HCV reactive samples were submitted to real time PCR (Cobas Taqman HCV 2.0, Roche, USA), and samples with detectable HCV RNA were also genotyped by INNOLIPA (Versant HCV Genotype Assay - LiPA, Bayer, Germany).
$\mathrm{HBsAg}$ and anti-HCV were assayed among saliva samples using commercial EIAs (HCVab, Radim and HBsAg One, Radim). A total of 61 paired saliva and serum samples were assayed for anti-HCV using an optimized commercial EIA ${ }^{6}$, and 46 paired saliva and serum samples were tested using a modified commercial HBsAg EIA $^{5}$.

\section{Statistical analysis}

Descriptive statistics were generated for the responses, and exact Fisher's test and unpaired t test with Welch correction were used to compare the categorical and continuous variables according to the anti-HBc status. Variables selected for statistical significance $(p<0.20)$ in the bivariate analysis were entered into the logistic regression model in a stepwise fashion and $p$-value $<0.05$ were considered statistically significant at the multivariate analysis. Sensitivity, specificity, positive (PPV), and negative (NPV) predictive values, and kappa index were determined for HBsAg and anti-HCV assays in saliva samples.

All analyses were performed with the Statistical Package for the Social Sciences (SPSS for Windows, release 20.0; SPSS, Inc., Chicago, IL, USA).

\section{RESULTS}

\section{Demographic and risk factors for HBV and HCV} infection

Most individuals were Caucasian $(44.4 \%, \mathrm{n}=40)$, single $(56.7 \%, \mathrm{n}=51)$, had primary school education level $(54.4 \%$, $\mathrm{n}=49$ ), and had a wage of up to US $\$ 876.00$ per month $(54.4 \%, \mathrm{n}=49)$. Mean age was $33.5 \pm 11.2$ years old (varying from 18 to 74 years old). Risk factors are depicted in Table 1 .

Prevalence of HBV and HCV markers among serum samples and evaluation of risk factors

Prevalences of anti-HCV, HBsAg, anti-HBc and antiHBs were: $5.6 \%(\mathrm{n}=5), 0 \%(\mathrm{n}=0), 15.7 \%(\mathrm{n}=14)$ and $29.2 \%$ $(\mathrm{n}=26)$. Twelve $(13.3 \%)$ individuals had previous HBV infection (anti-HBc/anti-HBs reactive) and 14 (15.5\%) were considered vaccinated individuals (isolated antiHBs reactive). Out of 5 anti-HCV reactive individuals, 4 presented HCV RNA (3 had genotype 1 and one had genotype 3). Risk factors evaluation was not performed for anti-HCV due to the low number of infected individuals.

At the bivariate analysis, anti-HBc reactivity was associated to age (higher mean age), marital status (single), having tattoo, having earring, history of emergency care, 
Table 1 - Risk factors for HBV and HCV acquisition among the studied population $(\mathrm{n}=90)$

\begin{tabular}{lcc}
\hline \multirow{2}{*}{ Risk Factors } & \multicolumn{2}{c}{ Overall Sample } \\
\cline { 2 - 3 } & $\mathrm{n}$ & $\%$ \\
\hline Recipient of blood transfusion & 3 & 3.3 \\
$\quad$ - Before 1994 & 1 & 1.1 \\
History of hemodialysis & 1 & 1.1 \\
Tattoo & 37 & 41.1 \\
Piercing & 7 & 7.7 \\
Earing & 48 & 53.3 \\
Share razor & 23 & 25.5 \\
Share toothbrush & 17 & 18.9 \\
History of dental treatment & 60 & 66.6 \\
History of emergency care & 43 & 47.7 \\
Illicit Drugs use once in lifetime & 36 & 40.0 \\
More than 5 sexual partners per year & 17 & 18.9 \\
Codon use during intercourse & & \\
$\quad$ - Never & 18 & 20.0 \\
$\quad$ - Rarely & 32 & 35.5 \\
$\quad$ - Frequently & 7 & 7.7 \\
Oral intercourse & 55 & 61.1 \\
Anal intercourse & 39 & 43.3 \\
History of sexual transmitted disease & 19 & 21.1 \\
\hline & \multicolumn{2}{c}{} \\
\hline
\end{tabular}

and the use of codon during intercourse (Table 2), but none of them was significant for the multivariate analysis.

\section{Evaluation of substance consumption}

Mean score for ASSIST instrument regarding alcohol consumption was $16.74 \pm 4.75$. All individuals had history of alcohol use, $38.9 \%(n=35)$ were classified as abusive alcohol users and $56.7 \%(\mathrm{n}=51)$ were categorized as addicts. Participants also reported the consumption of other substances at least once in their lifetime, being the most prevalent: cocaine and crack $(80 \%, \mathrm{n}=72)$, tobacco $(70 \%$, $\mathrm{n}=63)$ and marijuana $(64.4 \%, \mathrm{n}=58)$. No one reported the use of injected drugs. Most participants reported intake alcohol as being daily $(34.4 \%, \mathrm{n}=31)$ or weekly $(5.6 \%$, $\mathrm{n}=05)$, followed by $17.8 \%(\mathrm{n}=16)$ who drink once or twice in a month.

Among those that reported consumption of cocaine at least once in life, all were anti-HCV reactive and 9 were anti-HBc reactive. Among five anti-HCV individuals, 3 were considered moderate risk for alcohol, marijuana and cocaine, and other two were considered low risk for these drugs. Among anti-HBc reactive individuals ( $\mathrm{n}=14)$, moderate risk for alcohol, marijuana and cocaine was found in 6, 4 and 4 individuals, respectively.

\section{Evaluation of saliva samples for HBsAg and anti-HCV detection among alcoholic patients}

HBsAg detection in saliva samples demonstrated 100\% of specificity ( 46 saliva and 46 serum negative samples), but it was not possible to calculate sensitivity, since no one had HBsAg in serum. Anti-HCV test in saliva demonstrated $100 \%$ of sensitivity ( 4 saliva and 4 serum positive) ( $95 \%$ confidence interval, CI: $39.7 \%$ to $100 \%)$ and $94.7 \%$ of specificity (53 saliva out of 57 serum) (95\% CI: $85.4 \%$ to $98.9 \%$ ). PPV and NPV were $57.1 \%$ (95\% CI: $18.4 \%$ to $90.1 \%$ ) and $100 \%$ (95\% CI: $93.4 \%$ to $100 \%$ ), respectively. Kappa index indicated a good agreement between anti-HCV results from serum and saliva (k: 0.702, 95\% CI: 0.389-1.000).

Table 2 - Bivariate and multivariate analysis of demographic and risk factors associated to anti-HBc prevalence among 90 alcoholic patients

\begin{tabular}{|c|c|c|c|c|c|}
\hline \multirow[b]{2}{*}{ Variables } & \multicolumn{2}{|c|}{ Total Anti- HBc } & \multirow{2}{*}{$\begin{array}{c}\text { Bivariate } \\
\text { analysis } \\
P \text {-value }\end{array}$} & \multirow{2}{*}{$\begin{array}{c}\text { Multivariate } \\
\text { analysis } \\
\text { OR }(95 \% \mathrm{Cl})\end{array}$} & \multirow[b]{2}{*}{$P$-value } \\
\hline & $\begin{array}{l}\text { Reactive } \\
(n=14)\end{array}$ & $\begin{array}{c}\text { Non-reactive } \\
\quad(n=76)\end{array}$ & & & \\
\hline Age (mean \pm standard deviation, years) ${ }^{*}$ & $42.72 \pm 10.34$ & $31.82 \pm 10.45$ & 0.002 & $\begin{array}{c}1.993 \\
(0.247-16.063)\end{array}$ & 0.517 \\
\hline Marital Status, single & $9(64.3 \%)$ & $45(59.2 \%)$ & 0.063 & $\begin{array}{c}1.108 \\
(0.374-3.285)\end{array}$ & 0.853 \\
\hline Previous history of tattoo & $3(21.4 \%)$ & $34(44.7 \%)$ & 0.103 & $\begin{array}{c}4.424 \\
(0.636-30.754)\end{array}$ & 0.133 \\
\hline Previous history of earring & $5(35.7 \%)$ & $43(56.6 \%)$ & 0.112 & $\begin{array}{c}2.168 \\
(0.293-16.008)\end{array}$ & 0.448 \\
\hline History of emergency care & $10(71.4 \%)$ & $33(43.4 \%)$ & 0.129 & $\begin{array}{c}0.107 \\
(0.008-1.455)\end{array}$ & 0.093 \\
\hline Did not use codon during intercourse & $6(42.8 \%)$ & $43(56.6 \%)$ & 0.185 & $\begin{array}{c}0.908 \\
(0.5514-1.607)\end{array}$ & 0.742 \\
\hline
\end{tabular}

*Unpaired t test with Welch correction. 'Exact Fisher's test was used. 


\section{DISCUSSION}

The present study shows low HBV and HCV prevalences among alcoholic individuals compared to other studies in Brazil, Turkey, Sweden ${ }^{2-4,8}$, which could be due to the absence of injecting drug users.

Anti-HCV prevalence (5.6\%) was lower than reported among alcoholic patients from the South of Brazil (15\%) and non-injecting drug users $(19.4 \%)^{3,9}$, but higher than reported in general population ${ }^{10}$. This low prevalence could be due to the low number of individuals included in the present study compared to previous studies or to the difference of $\mathrm{HCV}$ prevalence according to the geographical region of Brazil. The data reinforce- the need for testing for anti-HCV in this group to identify HCV cases. In addition, most of the alcoholic patients showed active infection (anti-HCV/HCV RNA) and had HCV genotype 1, the same as observed among alcoholic individuals and the general population in Brazil ${ }^{3,10}$.

Previous HBV infection (anti-HBc reactivitiy) was observed in $15.7 \%$ of individuals similar to what is observed among alcoholic patients from the South of Brazil $(14.7 \%)^{4}$. HBV immunity was low $(29.2 \%)$ compared to other alcoholic individuals $(54.5 \%)$ in Brazil $^{4}$ reflecting the low concern about HBV risk in the population studied. Anti-HBc reactivity was associated to invasive procedures, like tattoo, history of emergency care, or sexual activities like the use of condom during intercourse as previously observed $^{4}$. However, this association was not found in the multivariate analysis probably due to the low prevalence of anti-HBc and the number of recruited individuals.

High efficiency of anti-HCV testing in saliva samples was observed as demonstrated in the general population ${ }^{6}$, showing the applicability of this method for HCV diagnosis in alcoholic individuals. Saliva samples are easier to collect than blood, showing a lower risk of contamination and greater acceptability. Nowadays rapid tests using saliva samples are available and could increase the access to diagnosis in remote areas ${ }^{11}$. It was not possible to evaluate the sensitivity of HBsAg detection in this population, but high specificity was previously shown ${ }^{5}$.

In conclusion, the low prevalence of $\mathrm{HBV}$ and the high prevalence of anti-HCV that were found reinforce the recommendation of $\mathrm{HBV}$ vaccination to avoid both acute and chronic cases, as well the HCV screening in this group to identify the cases for antiviral therapy.

Saliva sampling could be employed as an alternative for HCV diagnosis among alcoholic patients, which could increase the access of diagnosis in this group due to the easy collection, the lower risk of contamination, and the greater acceptability.

\section{ACKNOWLEDGEMENTS}

We thank the technicians of the Viral Hepatitis Laboratory for their technical assistance.

\section{FUNDING}

This research was supported by the Foundation for Supporting Research in Rio de Janeiro State (FAPERJ), the Brazilian National Counsel of Technological and Scientific Development (CNPq), the Coordination of Improvement of Higher Education Personnel (CAPES) and the Oswaldo Cruz Foundation (FIOCRUZ).

\section{CONFLICT OF INTERESTS}

All authors disclose no actual or potential conflict of interests including any financial, personal, or other relationships with people from organizations within three (3) years of the beginning the work submitted that could inappropriately influence (bias) their work.

\section{REFERENCES}

1. Macinko J, Mullachery P, Silver D, Jimenez G, Morais Neto OL. Patterns of alcohol consumption and related behaviors in Brazil: evidence from the 2013 National Health Survey (PNS 2013). PLoS One. 2015;10:e0134153.

2. Tekin F, Gunsar F, Erdogan EI, Sertoz RY, Karasu Z, Ersoz G, et al. Seroprevalence of hepatitis A, B, and C viruses in Turkish alcoholic cirrhotics and the impact of hepatitis B on clinical profile. J Infect Dev Ctries. 2015;9:254-8.

3. Galperim B, Cheinquer H, Stein A, Fonseca A, Lunge V, Ikuta N. Prevalence of hepatitis $C$ virus in alcoholic patients: role of parenteral risk factors. Arq Gastroenterol. 2006;43:81-4.

4. Pazeto DL, Pazeto CL, Bertolini DA, Hoss KA. Prevalência de marcadores sorológicos de hepatite $\mathrm{B}$ em pacientes internados para tratamento de alcoolismo em uma unidade de saúde mental do oeste catarinense. Rev Bras Anal Clin. 2012;44:87-92.

5. Cruz HM, da Silva EF, Villela-Nogueira CA, Nabuco LC, do Ó KM, Lewis-Ximenez LL, et al. Evaluation of saliva specimens as an alternative sampling method to detect hepatitis B surface antigen. J Clin Lab Anal. 2011;25:134-141.

6. Cruz HM, Marques VA, Villela-Nogueira CA, do Ó KM, LewisXimenez LL, Lampe E, et al. An evaluation of different saliva collection methods for detection of antibodies against hepatitis C virus (anti-HCV). J Oral Pathol Med. 2012; 41:793-800.

7. Humeniuk R, Henry-Edwards S, Ali R, Poznyak V, Monteiro M.. The Alcohol, Smoking and Substance Involvement Screening Test (ASSIST): manual for use in primary care. Geneva: WHO; 
2010. [cited 2016 Feb 9]. Available from: http://whqlibdoc. who.int/publications/2010/9789241599382_eng.pdf.

8. Befrits R, Hedman M, Blomquist L, Allander T, Grillner L, Kinnman N, et al. Chronic hepatitis $\mathrm{C}$ in alcoholic patients: prevalence, genotypes, and correlation to liver disease. Scand J Gastroenterol. 1995;30:1113-8.

9. Oliveira-Filho AB, Sawada L, Pinto LC, Locks D, Bahia SL, Castro JA, et al. Epidemiological aspects of $\mathrm{HCV}$ infection in non-injecting drug users in the Brazilian state of Pará, eastern Amazon. Virol J. 2014;11:38
10. Pereira LM, Martelli CM, Moreira RC, Merchan-Hamman E, Stein AT, Cardoso MR, et al. Prevalence and risk factors of hepatitis C virus infection in Brazil, 2005 through 2009: a cross-sectional study. BMC Infect Dis. 2013;13:60.

11. Scalioni LP, Cruz HM, de Paula VS, Miguel JC, Marques VA, Villela-Nogueira CA, et al. Performance of rapid hepatitis C virus antibody assays among high- and low-risk populations. J Clin Virol. 2014;60:200-5. 